\title{
Parâmetros fisiológicos de mudas de copaíba sob diferentes substratos e condições de sombreamento
}

\author{
Physiological parameters in seedlings of copaiba under different shade conditions and substrates
}

\author{
Tiago Reis Dutra' Marilia Dutra Massad"I Reynaldo Campos Santana ${ }^{\text {III }}$
}

\section{RESUMO}

O presente trabalho teve como objetivo avaliar parâmetros fisiológicos de mudas de copaíba produzidas sob o efeito de diferentes níveis de sombreamento e tipos de substratos. O experimento teve a duração de 130 dias e foi conduzido em blocos casualizados no esquema fatorial $5 \times 4$, com cinco substratos: Bioplant ${ }^{\circledR} ; 70 \%$ vermiculita $+30 \%$ casca de arroz carbonizada; $40 \%$ vermiculita $+30 \%$ casca de arroz carbonizada $+30 \%$ fibra de coco; $50 \%$ vermiculita $+30 \%$ casca de arroz carbonizada $+20 \%$ areia; $70 \%$ vermiculita + $15 \%$ casca de arroz carbonizada $+15 \%$ vermicomposto de resíduo de indústria têxtil; quatro níveis de sombreamento (100, 70, 50 e 30\% do pleno sol) e três repetições. O nível de sombreamento de $50 \%$ em relação ao pleno sol possibilitou a produção de mudas de copaíba com maiores teores de clorofila $b$ e clorofila total, além de proporcionar os menores valores de transpiração diária e ao longo do dia das plantas. A área foliar, os teores de clorofila e a transpiração das mudas de copaíba independem do tipo de substrato, podendo ser produzidas em qualquer um dos meios de crescimento avaliados.

Palavras-chave: Copaifera langsdorffii Desf., sombreamento, radiação luminosa, teor de clorofila.

\section{ABSTRACT}

This research aimed to evaluate physiological parameters of seedlings of copaiba produced under the effect of different shading levels and types of substrates. The experiment lasted 130 days and was conducted in randomized blocks in factorial scheme $5 \times 4$ with five substrates: Bioplant ${ }^{\circledR}, 70 \%$ vermiculite $+30 \%$ rice hulls, $40 \%$ vermiculite $+30 \%$ rice charred hulls $+30 \%$ fiber coconut, $50 \%$ vermiculite $+30 \%$ rice charred hulls $+20 \%$ sand, $70 \%$ vermiculite $+15 \%$ rice charred hulls + $15 \%$ vermicompost residue of textile industry; four shading levels (100, 70, 50 and 30\% full sun) and three replications. The shade level of $50 \%$ compared to full sun, enabled the production of seedlings of Copaiba with higher concentrations of chlorophyll $b$ and total chlorophyll, and provided the lowest daily transpiration throughout the day and the plants. The leaf area, chlorophyll content and transpiration of seedlings of Copaiba independent of the substrate and can be produced in any of the growth media evaluated.

Key words: Copaifera langsdorffii Desf., shading, light radiation, chlorophyll.

\section{INTRODUÇÃO}

O bioma cerrado possui cerca de dois milhões de $\mathrm{km}^{2}$, área correspondente a aproximadamente $23,9 \%$ de todo o território brasileiro (BRASIL, 2007). Entre os representantes vegetais nativos do cerrado, a copaíba (Copaifera langsdorffii Desf.), espécie arbórea da família Leguminosae (Caesalpinioideae), é de ocorrência natural principalmente no estado de Minas Gerais, Goiás, Mato Grosso do Sul, São Paulo e Paraná, sendo também encontrada em outros estados brasileiros abrangidos pelo mesmo bioma (NOLETO \& SILVEIRA, 2004).

A espécie pode ser empregada na arborização rural e urbana, para plantio em áreas degradadas e de

Instituto Federal de Educação, Ciência e Tecnologia do Norte de Minas Gerais (IFNMG), Fazenda Varginha, Km 02, Rodovia MG404, Zona Rural, 39560-000, Salinas, MG, Brasil. E-mail: tiagoreisdutra@gmail.com. Autor para correspondência.

IInstituto Federal de Educação, Ciência e Tecnologia do Paraná (IFPR), Irati, PR, Brasil.

IIIUniversidade Federal dos Vales do Jequitinhonha e Mucuri (UFVJM), Diamantina, MG, Brasil. 
preservação permanente, assim como na fabricação de móveis, entretanto o sucesso do plantio e do estabelecimento inicial de espécies arbóreas nativas com fins econômicos ou conservacionistas depende, em grande parte, da qualidade morfofisiológica de suas mudas (LORENZI, 2002). Vários fatores exercem influências no desenvolvimento de mudas durante a fase de viveiro, como, por exemplo, a composição do substrato e a radiação luminosa.

O substrato é um insumo importante dentro do sistema de produção de mudas. Diferentes materiais têm sido usados para sua composição, como a casca de arroz carbonizada, serragem, turfa, vermiculita, composto orgânico, esterco bovino, moinha de carvão, material de subsolo, bagaço de cana, acícula de pinus e areia lavada (COSTA et al., 2005). O estudo do arranjo percentual desses componentes é de grande importância, já que poderão ser fonte de nutrientes além de fornecerem suporte estrutural ao desenvolvimento radicular da planta. Dessa forma, algumas propriedades químicas e físicas devem ser consideradas na escolha do substrato, como sua capacidade de retenção de água, porosidade, teor nutricional e capacidade de troca de cátions, além do baixo custo e disponibilidade nas proximidades da região de consumo (GOMES \& SILVA, 2004).

A luz é um fator ecológico de fundamental importância, capaz de interferir sobre todos os estádios de desenvolvimento das plantas e em seus numerosos processos fisiológicos. Estudos relacionando a disponibilidade da radiação luminosa para produção de mudas de espécies arbóreas de boa qualidade são de extrema importância para o desenvolvimento das atividades florestais (LIMA et al., 2010), sendo a prática de sombreamento artificial realizada por meio do uso de telas de sombreamento, um método muito utilizado no estudo das necessidades luminosas das diferentes espécies em condições de viveiro.

Há uma grande diversidade de respostas das plantas à energia luminosa. Sua aclimatação à luz incidente ocorre no sentido de maximizar o ganho total de carbono, entretanto essa resposta pode variar consideravelmente entre espécies, de acordo com sua capacidade de aclimatação e a dependência da quantidade ou qualidade da luz (PACHECO \& PAULILO, 2009).

Considerando a importância da fase de produção de mudas para o cultivo de espécies florestais nativas e a carência de conhecimentos básicos para sua produção, o objetivo deste trabalho foi avaliar parâmetros fisiológicos de mudas de copaíba produzidas sob o efeito de diferentes níveis de sombreamento e tipos de substratos.

\section{MATERIAL E MÉTODOS}

As sementes de copaíba foram coletadas de sete matrizes localizadas no município de São Gonçalo do Rio das Pedras-MG, a 1090m de altitude, latitude 18²3'21,9' S e longitude 4332'30,2' W, em setembro de 2008. O estudo foi realizado durante os meses de dezembro de 2008 a abril de 2009 com médias de temperaturas mínima e máxima de 14,6 e $28,9^{\circ} \mathrm{C}$, respectivamente, e umidade relativa do ar de $80,4 \%$.

O experimento teve a duração de 130 dias, sendo conduzido em blocos casualizados, com três repetições, no esquema fatorial $5 \times 4$, sendo avaliados cinco substratos: Bioplant ${ }^{\circledR}$ (composto por: casca de pinus, fibra de côco, agentes agregantes, vermiculita, complementos minerais), $70 \%$ vermiculita $+30 \%$ casca de arroz carbonizada $(70 \mathrm{~V}+30 \mathrm{CA}), 40 \%$ vermiculita $+30 \%$ casca de arroz carbonizada $+30 \%$ fibra de coco $(40 \mathrm{~V}+30 \mathrm{CA}+30 \mathrm{FC}), 50 \%$ vermiculita $+30 \%$ casca de arroz carbonizada $+20 \%$ areia lavada $(50 \mathrm{~V}+30 \mathrm{CA}+20 \mathrm{~A}), 70 \%$ vermiculita $+15 \%$ casca de arroz carbonizada $+15 \%$ vermicomposto de resíduo de indústria têxtil (composto por: algodão, munha de carvão e esterco bovino) $(70 \mathrm{~V}+15 \mathrm{CA}+15 \mathrm{VC})$; e quatro níveis de sombreamento: $100,70,50$ e $30 \%$ do pleno sol. Cada parcela foi composta por 10 plantas.

A caracterização química dos substratos foi realizada pelo Laboratório de Fertilidade do Solo da UFVJM. As características físicas porosidade total, macroporosidade, microporosidade, densidade aparente e capacidade máxima de retenção de água dos substratos foram determinadas por meio do método proposto por CARVALHO \& SILVA (1992) (Tabela 1). Antes dos substratos serem acondicionados em tubetes cônicos com capacidade volumétrica de $280 \mathrm{~cm}^{3}$, esses receberam $7,0 \mathrm{~g}$ $\mathrm{dm}^{-3}$ de Osmocote ${ }^{\circledR}$ de liberação lenta, por até cinco a seis meses, contendo 15-09-12 (N-P-K) + Micronutrientes.

Para quebra de dormência, as sementes foram imersas em ácido sulfúrico concentrado (98\%) por cinco minutos e lavadas em água corrente por 10 minutos. Em seguida, colocaram-se três sementes por tubete, já preenchidos com os substratos, dispostos em bandejas de polipropileno tipo caixa $(620 \times 420 \times 165 \mathrm{~mm})$. As bandejas foram colocadas em casa de vegetação coberta com filme plástico (150 microns de espessura) com tela de sombreamento de $50 \%$ sob irrigação por nebulização intermitente à vazão de $7 \mathrm{~L} \mathrm{~h}^{-1}$.

Quarenta dias após a semeadura, realizou-se o desbaste, deixando-se apenas a planta mais vigorosa, 
Tabela 1 - Características químicas e físicas dos substratos utilizados na produção de mudas de copaíba.

\begin{tabular}{|c|c|c|c|c|c|}
\hline \multirow{3}{*}{ Características } & \multirow{2}{*}{\multicolumn{5}{|c|}{----Substrato }} \\
\hline & & & & & \\
\hline & Bioplant ${ }^{\circledR}$ & $70 \mathrm{~V}+30 \mathrm{CA}$ & $40 \mathrm{~V}+30 \mathrm{CA}+30 \mathrm{FC}$ & $50 \mathrm{~V}+30 \mathrm{CA}+20 \mathrm{~A}$ & $70 \mathrm{~V}+15 \mathrm{CA}+15 \mathrm{VC}$ \\
\hline $\mathrm{C}$, dag $\mathrm{kg}^{-1}$ & 20,47 & 1,67 & 9,32 & 1,59 & 2,06 \\
\hline $\mathrm{N}$, dag kg ${ }^{-1}$ & 0,31 & 0,13 & 0,11 & 0,14 & 0,18 \\
\hline M.O, dag kg ${ }^{-1}$ & 35,21 & 2,87 & 16,03 & 2,73 & 3,54 \\
\hline pH, água & 5,0 & 6,7 & 6,7 & 6,6 & 6,7 \\
\hline $\mathrm{P}, \mathrm{mg} \mathrm{dm}^{-3}$ & 935 & 69 & 37 & 70,9 & 64,0 \\
\hline $\mathrm{K}, \mathrm{mg} \mathrm{dm}^{-3}$ & 1.061 & 313 & 240 & 272 & 451 \\
\hline $\mathrm{Ca}, \mathrm{cmol}_{\mathrm{c}} \mathrm{dm}^{-3}$ & 15,9 & 4,4 & 1,3 & 1,7 & 7,9 \\
\hline $\mathrm{Mg}, \mathrm{cmol}_{\mathrm{c}} \mathrm{dm}^{-3}$ & 4,6 & 11,0 & 8,4 & 6,0 & 7,2 \\
\hline $\mathrm{H}+\mathrm{Al}, \mathrm{cmol}_{\mathrm{c}} \mathrm{dm}^{-3}$ & 5,8 & 1,7 & 1,5 & 1,5 & 1,5 \\
\hline $\mathrm{Al}, \mathrm{cmol}_{\mathrm{c}} \mathrm{dm}^{-3}$ & 0,9 & 0,2 & 0,3 & 0,1 & 0,2 \\
\hline $\mathrm{t}, \mathrm{cmol}_{\mathrm{c}} \mathrm{dm}^{-3}$ & 24,1 & 16,4 & 10,6 & 9,7 & 16,5 \\
\hline $\mathrm{T}, \mathrm{cmol}_{\mathrm{c}} \mathrm{dm}^{-3}$ & 29,0 & 17,9 & 11,8 & 11,1 & 17,8 \\
\hline $\mathrm{SB}, \mathrm{cmol}_{\mathrm{c}} \mathrm{dm}^{-3}$ & 23,2 & 16,2 & 10,3 & 9,6 & 16,3 \\
\hline $\mathrm{m}, \%$ & 4,0 & 1,0 & 3,0 & 1,0 & 1,0 \\
\hline $\mathrm{V}, \%$ & 80,2 & 91,0 & 87,0 & 86,0 & 92,0 \\
\hline Porosidade Total, $\mathrm{dm}^{3} \mathrm{dm}^{-3}$ & 80,6 & 69,3 & 69,8 & 61,6 & 68,9 \\
\hline Macroporosidade, $\mathrm{dm}^{3} \mathrm{dm}^{-3}$ & 34,7 & 33,9 & 37,7 & 33,5 & 35,7 \\
\hline Microporosidade, $\mathrm{dm}^{3} \mathrm{dm}^{-3}$ & 45,9 & 35,4 & 32,1 & 28,0 & 33,2 \\
\hline Densidade aparente, $\mathrm{kg} \mathrm{dm}^{-3}$ & 0,1 & 0,2 & 0,1 & 0,5 & 0,3 \\
\hline CMRA, $\mathrm{mL} 55 \mathrm{~cm}^{-3}$ & 25,3 & 19,5 & 17,7 & 15,4 & 18,3 \\
\hline
\end{tabular}

M.O. = matéria orgânica; $\mathrm{t}=$ capacidade efetiva de troca de cátions; $\mathrm{T}=$ capacidade de troca de cátions; $\mathrm{SB}=\mathrm{soma}$ de bases; $\mathrm{m}=$ saturação por alumínio; $\mathrm{V}=$ saturação por bases; $\mathrm{CMRA}=$ Capacidade máxima de retenção de água. Bioplant ${ }^{\mathbb{R}} ; 70 \%$ vermiculita $+30 \%$ casca de arroz carbonizada $(70 \mathrm{~V}+30 \mathrm{CA}) ; 40 \%$ vermiculita $+30 \%$ casca de arroz carbonizada $+30 \%$ fibra de côco $(40 \mathrm{~V}+30 \mathrm{CA}+30 \mathrm{FC}) ; 50 \%$ vermiculita + $30 \%$ casca de arroz carbonizada $+20 \%$ areia $(50 \mathrm{~V}+30 \mathrm{CA}+20 \mathrm{~A}) ; 70 \%$ vermiculita $+15 \%$ casca de arroz carbonizada $+15 \%$ vermicomposto de resíduo de indústria têxtil $(70 \mathrm{~V}+15 \mathrm{CA}+15 \mathrm{VC})$.

além de realizada a redistribuição dos tubetes, intercalando-os entre as células da bandeja. Em seguida, as mudas foram transferidas para área de crescimento a céu aberto, onde foram submetidas aos tratamentos de sombreamento (100, 70,50 e $30 \%$ do pleno sol). As diferentes intensidades de sombreamento foram obtidas por meio da construção de estruturas em tubos PVC com $2,0 \mathrm{~m}$ de comprimento $\times 2,0 \mathrm{~m}$ de largura $\times 1,5 \mathrm{~m}$ de altura, recobertas com telas de polipropileno preto ("sombrite"). As irrigações nesse setor foram realizadas por microaspersores bailarinas com vazão de $240 \mathrm{~L} \mathrm{~h}^{-1}$ a cada duas horas no período de 7 às 17 horas, durante dois minutos para os sombreamentos de 50 e $30 \%$ do pleno sol e por três minutos para os de 100 e $70 \%$, de modo que a quantidade de água nos substratos fosse mantida próxima àquela da capacidade de campo.

Duas adubações de cobertura foram realizadas, sendo a primeira com uma solução de $3,0 \mathrm{~g} \mathrm{~L}^{-1}$ de $\mathrm{Ca}\left(\mathrm{NO}_{3}\right)_{2}$ aos 40 dias após a semeadura. Para a segunda adubação, aos 90 dias após a semeadura, utilizou-se uma solução contendo, em mg L-1: 5,5 de $\mathrm{Ca}\left(\mathrm{NO}_{3}\right)_{2}, 1,5$ de $\mathrm{MgSO}_{4}, 2,63$ de $\mathrm{KCl}, 0,9$ de $\mathrm{NH}_{4} \mathrm{H}_{2} \mathrm{PO}_{4}$
(MAP), 2,0 de $\left(\mathrm{NH}_{4}\right)_{2} \mathrm{SO}_{4}, 0,035 \mathrm{H}_{3} \mathrm{BO}_{3}, 0,004 \mathrm{de} \mathrm{CuSO}_{4}$, 0,015 de $\mathrm{ZnSO}_{4}, 0,017$ de $\mathrm{MnSO}_{4}, 0,02$ de ferrilene, 2,5 de superfosfato simples.

Aos 130 dias, foram mensuradas a área foliar; os teores de clorofila $a, b$ e total; a razão clorofila $a / b ; 0$ teor relativo de água na folha e a transpiração das mudas. $\mathrm{A}$ área foliar das mudas $\left(\mathrm{AF} ; \mathrm{cm}^{2}\right)$ foi determinada, gravimetricamente, pelo peso do molde das folhas em papel, comparado com a massa de um padrão com área conhecida e a massa seca da folha (g) realizada em duas plantas por repetição em cada tratamento, determinada após a secagem em estufa a $65^{\circ} \mathrm{C}$ até peso constante.

A determinação dos teores de clorofila foi realizada em três plantas por repetição em cada tratamento, tomadas ao acaso, no horário entre $07 \mathrm{e} 08$ horas da manhã. De cada planta, seccionaram-se três folhas adultas de mesma idade completamente expandidas, localizadas entre o ápice e a base da planta, sendo imediatamente acondicionadas em papel alumínio e caixa de isopor com água gelada. A extração da clorofila foi feita em acetona $80 \%$ e a absorbância da solução resultante mensurada por espectrofotometria (645 e 
$663 \mathrm{~nm})$. A quantificação das clorofilas $a, b$, total e razão clorofila $a / b$ foi realizada segundo ARNON (1949).

Para determinação do teor relativo de água na folha (TRF; \%), foram usadas 180 plantas (três por repetição) e adotado o método descrito por NOGUEIRA et al. (2001). Para determinação da transpiração das mudas, adotou-se metodologia descrita por SILVA et al. (2004), obtendo-se os resultados por meio do método de pesagens (ou determinação das massas). Para obtenção da estimativa da transpiração diária $\left(\mathrm{mg} \mathrm{m}^{2} \mathrm{~s}^{-1}\right)$ das plantas por unidade de área, relacionou-se a perda de água com a área foliar. Do mesmo modo, foram obtidos os valores da transpiração ao longo do dia $\left(\mathrm{mg} \mathrm{m}^{2} \mathrm{~s}^{-1}\right)$ durante os intervalos de 8-10h; 10-12h; 12-14h; 14-16h; e 16-18h para cada nível de sombreamento testado.

Todas as plantas, após realização das mensurações anteriores, foram colhidas e separadas em folhas e caule-raiz e, em seguida, foram lavadas em água corrente e secas em estufa com circulação forçada de ar a aproximadamente $65^{\circ} \mathrm{C}$ até peso constante, obtendo-se a massa seca de folhas (MSF, g planta $^{-1}$ ) e a massa seca de caule-raiz (MSCR, g planta ${ }^{-1}$ ). A partir dos dados primários, variáveis subsequentes foram determinadas: massa seca total $\left(\mathrm{MST}=\mathrm{MSF}+\mathrm{MSCR}, \mathrm{g} \mathrm{planta}^{-1}\right)$, razão de área foliar (RAF, área foliar/massa seca total; $\mathrm{cm}^{2} \mathrm{~g}^{-1}$ ), massa foliar específica (MFE, massa seca da folha/área foliar; $\mathrm{g} \mathrm{cm}^{-2}$ ) e área foliar específica (AFE, área foliar/massa seca de folhas; $\mathrm{cm}^{2} \mathrm{~g}^{-1}$ ).

Os dados foram submetidos à análise de variância e, quando o efeito do tipo de substrato foi significativo, as médias foram comparadas pelo teste de Tukey $(\mathrm{P}<0,05)$. O efeito dos níveis de sombreamento foram analisados por meio de regressões e o valor de $\mathrm{F}$ foi corrigido; sendo apresentadas somente as equações cujos coeficientes de maior grau foram significativos $(\mathrm{P}<0,05)$. Todas as análises estatísticas foram realizadas utilizando-se o software Statistica 8.0.

\section{RESULTADOS E DISCUSSÃO}

O efeito da interação entre os principais fatores avaliados (tipo de substrato e níveis de sombreamento) foi significativo para a área foliar, teor relativo de água na folha, clorofila $a, b$, total e relação clorofila $a / b$. Verifica-se que a reposta das plantas em relação aos níveis de sombreamento e tipos de substrato foi muito distinta (Tabela 2). Observa-se que em $67 \%$ dos casos não ocorreu o ajuste da equação a um nível de até $5 \%$ de probabilidade, indicando não haver diferença entre os níveis de sombreamento avaliados.
As mudas de copaíba crescidas em $40 \mathrm{~V}+30 \mathrm{CA}+30 \mathrm{FC} \mathrm{e} 50 \mathrm{~V}+30 \mathrm{CA}+20 \mathrm{~A}$ apresentaram ajuste linear crescente em resposta ao efeito dos níveis de sombreamentos testados sobre sua área foliar. O aumento da área foliar é uma das estratégias utilizadas pela planta para assegurar seu rendimento fotossintético, tornandose dessa forma mais eficiente em baixa radiação luminosa. SILVA et al. (2007), avaliando o crescimento de mudas de Hymenaea parvifolia Huber., também observaram maior incremento de área foliar nas mudas mantidas sob maiores níveis de sombreamento.

A variável área foliar específica (AFE) não sofreu efeito significativo dos principais fatores avaliados. Uma das maneiras que a planta pode aumentar a interceptação total da luz é por meio do incremento de sua área foliar específica. Nota-se que, devido ao efeito não significativo dos níveis de sombra, as mudas de copaíba foram capazes de proporcionar um eficaz aproveitamento da luz mesmo sob sua baixa incidência. Resultado semelhante foi observado por GONÇALVES et al. (2005), no qual as plantas de Dipteryx odorata Aubl Willd (cumaru) sombreadas e a pleno sol não apresentaram diferença entre seus valores de AFE, porém, para Switenia macrophylla King (mogno), os autores verificaram que as folhas de sol foram três vezes menores quando comparadas com as folhas de sombra.

Para a variável teor relativo de água na folha (TRF), houve ajuste da equação e boa correlação entre os níveis de sombra aplicados apenas para o substrato $70 \mathrm{~V}+15 \mathrm{CA}+15 \mathrm{VC}$ (Tabela 2), no qual a elevação dos níveis de sombreamento proporcionou o aumento do TRF, atingindo o máximo valor (87\%) com 61\% do pleno sol, em resposta ao seu ajuste quadrático. Os demais substratos não apresentaram ajuste de equação (Tabela 2), indicando não haver diferença na quantidade de água armazenada nas folhas das mudas crescidas sob os diferentes níveis de sombreamento estudados.

Verificou-se que a clorofila $b$ foi significativamente afetada pelos níveis de sombreamento em três dos cinco substratos avaliados. Para o Bioplant ${ }^{\mathbb{R}}$, ocorreu uma resposta linear crescente, entretanto, no $70 \mathrm{~V}+30 \mathrm{CA}$ e $70 \mathrm{~V}+15 \mathrm{CA}+15 \mathrm{VC}$, o efeito quadrático possibilitou a determinação do maior valor de clorofila $b$ de suas mudas $\left(0,362\right.$ e $\left.0,257 \mu \mathrm{g} \mathrm{mg}^{-1}\right)$, obtidos em percentagens em relação ao pleno sol muito próximas, 55 e 54\%, respectivamente (Tabela 2). Resposta semelhante foi observada por REGO \& POSSAMAI (2006) quanto ao crescimento inicial e concentrações de clorofila em mudas de jequitibá-rosa (Cariniana legalis (Mart. O. Ktze) submetidas a diferentes períodos de permanência sob sombreamento. $\mathrm{O}$ aumento nos teores de clorofila $b$ 
Tabela 2 - Coeficientes das equações de regressão obtidos para as diferentes variáveis (y) analisadas em função do nível de sombreamento (x) para mudas de copaíba (Copaifera langsdorffii) aos 130 dias após semeadura.

\begin{tabular}{|c|c|c|c|c|}
\hline Substrato & Coeficientes & $\mathrm{R}^{2}$ & Coeficientes & $\mathrm{R}^{2}$ \\
\hline & Teor relativo de água na folha (\%) & & Clorofila a $\left(\mu \mathrm{g} \mathrm{mg}^{-1}\right)$ & \\
\hline 1 & $\hat{y}=\bar{y}=71,88$ & & $\hat{y}=\bar{y}=0,165$ & \\
\hline 2 & $\hat{y}=\bar{y}=66,47$ & & $\hat{y}=\bar{y}=0,191$ & \\
\hline 3 & $\hat{y}=\bar{y}=70,24$ & & $\hat{y}=\bar{y}=0,167$ & \\
\hline 4 & $\hat{y}=\bar{y}=80,42$ & & $\hat{y}=\bar{y}=0,171$ & \\
\hline \multirow[t]{2}{*}{5} & $\hat{y}=71,401+0,82^{* *} \mathrm{x}-0,0104 * * \mathrm{x}^{2}$ & 0,98 & $\hat{y}=\bar{y}=0,154$ & \\
\hline & Clorofila $\mathrm{b}\left(\mu \mathrm{g} \mathrm{mg}^{-1}\right)$ & & Clorofila a/b & \\
\hline 1 & $\hat{y}=0,2317+0,00035 * x$ & 0,77 & $\hat{y}=\bar{y}=0,675$ & \\
\hline 2 & $\hat{y}={ }_{0,193+0,007 * x-0,00008 * * x^{2}}$ & 0,84 & $\hat{y}=\bar{y}=0,635$ & \\
\hline 3 & $\hat{y}=\bar{y}=0,257$ & & $\hat{y}=0,7022-0,00125 * x$ & 0,73 \\
\hline 4 & $\hat{y}=\bar{y}=0,261$ & & $\hat{y}=0,64+0,003 * * x-0,00004 * x^{2}$ & 0,98 \\
\hline \multirow[t]{2}{*}{5} & $\hat{y}=0,159+0,0043 * x-0,00005 * x^{2}$ & 0,72 & $\hat{y}={ }_{1,004-0,017 * x+0,0002 * * x^{2}}$ & 0,99 \\
\hline & Clorofila total $\left(\mu \mathrm{g} \mathrm{mg}^{-1}\right)$ & & Área Folia $\left(\mathrm{cm}^{2}\right)$ & \\
\hline 1 & $\hat{y}=\bar{y}={ }_{0,392}$ & & $\hat{y}=\bar{y}=21,08$ & \\
\hline 2 & $\hat{y}=0,332+0,0115 * x-0,00013 * x^{2}$ & 0,79 & $\hat{y}=\bar{y}=21,34$ & \\
\hline 3 & $\hat{y}=\bar{y}=0,428$ & & $\hat{y}={ }_{15,1907+0,1526^{* *} \mathrm{x}}$ & 0,94 \\
\hline 4 & $\hat{y}=\bar{y}=0,435$ & & $\hat{y}=18,925+0,0398 * x$ & 0,82 \\
\hline 5 & $\hat{y}=\bar{y}=0,402$ & & $\hat{y}=\bar{y}=20,18$ & \\
\hline
\end{tabular}

Modelos ajustados: $\mathrm{y}=\mathrm{b} 0+\mathrm{b} 1 \mathrm{x} ; \mathrm{y}=\mathrm{b} 0+\mathrm{b} 1 \mathrm{x}+\mathrm{b} 2 \mathrm{x} 2$, níveis de significância dos coeficientes das regressões - * $(0,05>\mathrm{P}=0,01), * *(\mathrm{P}<0,01)$ $\hat{y}=\bar{y}=$ valor médio da variável. Substrato 1 (Bioplant), 2 (70V+30CA), $3(40 \mathrm{~V}+30 \mathrm{CA}+30 \mathrm{FC}), 4$ (50V+30CA+20A) e 5 $(70 \mathrm{~V}+15 \mathrm{CA}+15 \mathrm{VC}) . \mathrm{V}=\%$ de vermiculita; $\mathrm{CA}=\%$ de casca de arroz carbonizada; $\mathrm{FC}=\%$ de fibra de côco; VC $=\%$ de vermicomposto de resíduo de indústria têxtil; $\mathrm{A}=\%$ de areia lavada.

nas folhas submetidas à baixa disponibilidade de radiação luminosa representa um importante mecanismo de aclimatação à condição de menor energia luminosa.

A razão clorofila $a / b$ das mudas crescidas em $40 \mathrm{~V}+30 \mathrm{CA}+30 \mathrm{FC} \mathrm{e} 70 \mathrm{~V}+15 \mathrm{CA}+15 \mathrm{VC}$ apresentaram seus maiores valores médios nas plantas a $100 \%$ do pleno sol (Tabela 2). Entretanto, os valores dessa relação, de uma maneira geral, tendem a reduzir com a diminuição da radiação luminosa disponível, devido a uma maior produção e proporção relativa de clorofila $b$ em ambiente sombreado, efeito considerado compensatório da espécie vegetal. Essa resposta somente foi notada para as plantas crescidas no substrato $50 \mathrm{~V}+30 \mathrm{CA}+20 \mathrm{~A}$, no qual o maior valor da razão clorofila $a / b(0,681)$ foi alcançado com nível de $67 \%$ em relação ao pleno sol.

Apesar do efeito significativo da interação entre substrato e sombreamento para clorofila total, houve ajuste de regressão apenas para o substrato $70 \mathrm{~V}+30 \mathrm{CA}$ (Tabela2), sendo seu máximo valor $\left(0,588 \mu \mathrm{g} \mathrm{mg}^{-1}\right)$ alcançado com $55 \%$ do pleno sol. Resultado semelhante foi verificado por LIMA et al. (2010) para as espécies Hymenaea courbaril L. e Enterolobium contortisiliquum (Vell.). Segundo VALLADARES \& NIINEMETS (2008), plantas tolerantes à sombra possuem altos teores de clorofila e são capazes de atingir taxas fotossintéticas mais elevadas em condições de pouca luz.

Os valores médios da variável MFE, proporcionados pelos substratos $70 \mathrm{~V}+30 \mathrm{CA}\left(0,37 \mathrm{~g} \mathrm{~cm}^{-2}\right)$ $40 \mathrm{~V}+30 \mathrm{CA}+30 \mathrm{FC}\left(0,35 \mathrm{~g} \mathrm{~cm}^{-2}\right), 50 \mathrm{~V}+30 \mathrm{CA}+20 \mathrm{~A}\left(0,34 \mathrm{~g} \mathrm{~cm}^{-2}\right)$ e $70 \mathrm{~V}+15 \mathrm{CA}+15 \mathrm{VC}\left(0,33 \mathrm{~g} \mathrm{~cm}^{-2}\right)$, foram todos estatisticamente superiores, pelo teste de Tukey $(\mathrm{P}<0,05)$, quando comparados ao Bioplant ${ }^{\mathbb{R}}\left(0,23 \mathrm{~g} \mathrm{~cm}^{-2}\right)$. Segundo NAKAZONO et al. (2001), uma massa foliar específica mais elevada seria benéfica porque reduz a perda de água das mudas, além de promover o aumento do autosombreamento entre os cloroplastos. Uma explicação para esse resultado pode ser a menor relação $\mathrm{C} / \mathrm{N}$ desses substratos, o que proporcionou uma média de produção 
de massa seca de folhas $\left(0,70 \mathrm{~g}_{\text {planta }}{ }^{-1}\right) 148 \%$ superior ao Bioplant $^{\mathbb{R}}\left(0,47 \mathrm{~g} \mathrm{planta}^{-1}\right)$, refletindo assim em maior MFE.

Os valores da razão de área foliar (RAF) aumentaram de forma linear em resposta aos níveis de sombreamento $\left(\mathrm{y}=1,122+0,0044 * * \mathrm{x}, \mathrm{R}^{2}=0,95\right)$. Comportamento semelhante foi observado por LIMA et al. (2008) para o crescimento de mudas de Caesalpinia ferrea sob diferentes níveis de luminosidade, em que o sombreamento natural apresentou valores de RAF duas vezes superior à média dos demais tratamentos.

Em relação à transpiração diária das plantas de copaíba, houve uma redução progressiva com o aumento do nível de sombreamento ( $\mathrm{y}=9,776-0,1504 * *$ $\left.\mathrm{x}+0,0014 * * \mathrm{x}^{2}, \mathrm{R}^{2}=0,99\right)$, alcançando transpiração mínima $\left(5,765 \mathrm{mg} \mathrm{m}^{2} \mathrm{~s}^{-1}\right)$ com $47 \%$ do pleno sol. Esse resultado tem grandes implicações práticas, uma vez que a menor transpiração das mudas foi alcançada com sombreamento muito próximo ao amplamente utilizado em viveiros comerciais (50\%), viabilizando assim a produção de mudas da espécie, além de, nessas condições, a planta ser capaz de apresentar menor perda de água em seu desenvolvimento, exigindo menor demanda por irrigação.

A transpiração ao longo do dia (Figura 1) apresentou a mesma tendência verificada por LOPES et al. (2005), variando de acordo com as horas do dia. Nos horários mais quentes, por volta do meio-dia, as mudas apresentaram as maiores perdas de água. Observaram- se maiores variações nos tratamentos 100 e $70 \%$ do pleno sol (Figura 1). Segundo SILVA et al. (2004), uma maior variação na perda de água entre as horas mais quentes e menos quentes do dia pode ser resultado de resposta menos eficiente dos estômatos à transpiração. Notou-se também uma tendência mais homogênea na transpiração ao longo do dia nas mudas submetidas a $50 \%$ do pleno sol (Figura 1). Uma explicação para esse resultado pode estar atribuída à proximidade da porcentagem de sombra oferecida a essas plantas com o índice encontrado para atingir uma mínima transpiração diária (47\%), conferindo capacidade de se aclimatarem às condições de radiação luminosa oferecidas, tornando-as mais eficientes nas reações contra a desidratação, sendo capazes de promover fechamento mais rapidamente dos estômatos, resultando em uma menor perda de água por transpiração.

\section{CONCLUSÃO}

O nível de sombreamento de $50 \%$ possibilitou às plantas produção de maiores teores de clorofila $b$ e clorofila total, além dos menores valores de transpiração diária e ao longo do dia, sendo o mais recomendado para produção de mudas de copaíba. Aárea foliar, os teores de clorofila e a transpiração das mudas de copaíba independem do tipo de substrato, podendo ser produzidas em qualquer um dos meios de crescimento avaliados.

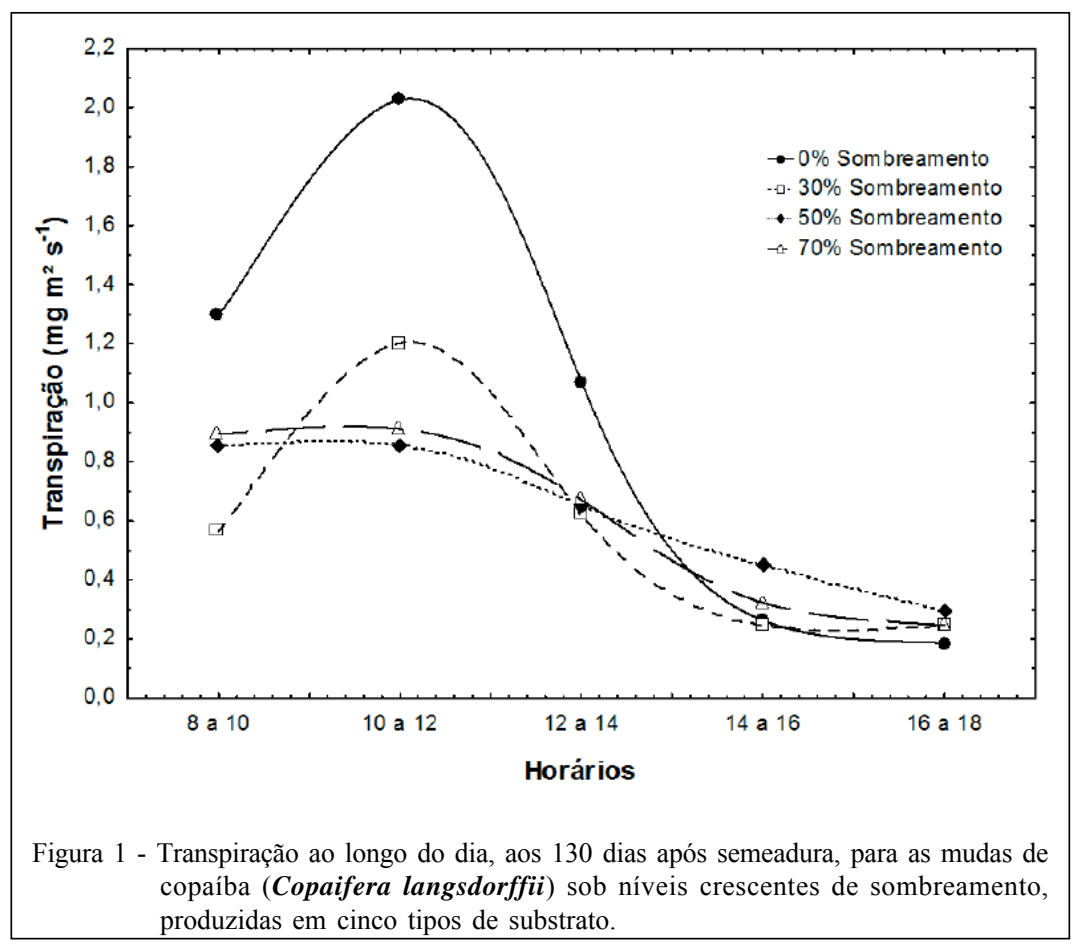

Ciência Rural, v.42, n.7, jul, 2012. 


\section{AGRADECIMENTOS}

À Fundação de Amparo à Pesquisa do Estado de Minas Gerais (FAPEMIG), pelo suporte financeiro dado a esta pesquisa.

\section{REFERÊNCIAS}

ARNON, D.I. Cooper enzymes in isolated chloroplasts Polyphenoloxidase in Beta vulgaris. Plant Physiology, v.24, p.1-15, 1949.

BRASIL. Ministério do Meio Ambiente (MMA). Mapas de cobertura vegetal dos biomas brasileiros. Brasília, 2007. Disponível em: < http://www.mma.gov.br/portalbio>. Acesso em: 28 dez. 2011.

CARVALHO, C.M.; SILVA, C.R. Determinação das propriedades físicas de substrato. Botucatu: Faculdade de Ciências Agronômicas: Universidade Estadual Paulista, 1992. 6p. (Notas de aulas práticas).

COSTA, M.C. et al. Substratos para produção de mudas de jenipapo (Genipa americana L.). Pesquisa Agropecuária Tropical, v.35, p.19-24, 2005. Disponível em: <www.revistas.ufg.br/index.php/ pat/article/view/2280/2243>. Acesso em: 12 mar. 2011.

GOMES, J.M.; SILVA, A.R. Os substratos e sua influência na qualidade de mudas. In: BARBOSA, J.G. et al. (Ed.). Nutrição e adubação de plantas cultivadas em substrato. Viçosa: Universidade Federal de Viçosa, 2004. p.190-225.

GONÇALVES, J.F.C. et al. Nutritional status and specific leaf area of mahogany and tonka bean under two light environments. Acta Amazonica, v.35, p.23-27, 2005. Disponível em: <http:/ /www.scielo.br/pdf/aa/v35n1/v35n1a03.pdf>. Acesso em: 08 mar. 2011. doi: 10.1590/S0044-59672005000100003.

LIMA, A.L.S. et al. Crescimento de Hymenaea courbaril L. var. stilbocarpa (Hayne) Lee et Lang. e Enterolobium contortisiliquum (Vell.) Morong (Leguminosae) sob diferentes níveis de sombreamento. Acta Amazonica, v.40, p.43-48, 2010. Disponível em: <http://acta.inpa.gov.br/fasciculos/40-1/PDF/ v40n1a06.pdf>. Acesso em: 21 fev. 2011. doi: 10.1590/S004459672010000100006 .

LIMA, J.D. et al. Efeitos da luminosidade no crescimento de mudas de Caesalpinia ferrea Mart. ex Tul. (Leguminosae, Caesalpinoideae). Acta Amazonica, v.38, p.5-10, 2008. Disponível em: <http://acta.inpa.gov.br/fasciculos/38-1/PDF/ v38n1a02.pdf>. Acesso em: 16 maio, 2011. doi: 10.1590/ S0044-59672008000100001.

LOPES, J.L.W. et al. Efeitos da irrigação na sobrevivência, transpiração e no teor relativo de água na folha em mudas de Eucalyptus grandis em diferentes substratos. Scientia
Forestalis, v.68, p.97-106, 2005. Disponível em: <http:// www.ipef.br/publicacoes/scientia/nr68/cap09.pdf>. Acesso em: 03 jun. 2011.

LORENZI, H. Árvores brasileiras. Nova Odessa: Plantarum, 2002. V.1, 368p.

NAKAZONO, E.M. et al. Crescimento inicial de Euterpe edulis Mart. em diferentes regimes de luz. Revista Brasileira de Botânica, v.24, p.173-179, 2001. Disponível em: <http:// www.scielo.br/pdf/rbb/v24n2/a07v24n2.pdf>. Acesso em: 27 abr. 2011 .

NOGUEIRA, R.J.M.C. et al. Alterações na resistência à difusão de vapor das folhas e relações hídricas em aceroleiras submetidas a déficit de água. Revista Brasileira de Fisiologia Vegetal, v.13, p.75-87, 2001. Disponível em: <http://www.scielo.br/pdf/ rbfv/v13n1/9275.pdf>. Acesso em: 15 fev. 2011.

NOLETO, L.G.; SILVEIRA, C.E.S. Propagação in vitro de Copaifera langsdorffii Desf. Revista Biotecnologia Ciência \& Desenvolvimento, v.33, p.109-120, 2004.

PACHECO, P.; PAULILO, M.T.S. Efeito da intensidade de luz no crescimento inicial de plantas de Cecropia glazioui Snethlage (Cecropiaceae). Insula: Revista de Botânica, v.38, p.28-41, 2009. Disponível em: <http://www.periodicos.ufsc.br/index.php/ insula $>$. Acesso em: 15 fev. 2011. doi: 10.5007/21784574.2009v38p28.

REGO, G.M.; POSSAMAI, E. Efeito do Sombreamento sobre o Teor de Clorofila e Crescimento Inicial do Jequitibá-rosa. Boletim de Pesquisa Florestal, v.53, p.179-194, 2006. Disponível em: <http://ww5.cnpf.embrapa.br/pfb/index.php/pfb/article/ view/210/160>. Acesso em: 04 fev. 2011.

SILVA, B.M.S. et al. Efeito da luz no crescimento de mudas de Hymenaea parvifolia Huber. Revista Árvore, v.31, p.10191026, 2007. Disponível em: <http://www.scielo.br/pdf/rarv/ v31n6/a06v31n6.pdf>. Acesso em: 20 jan. 2011. doi: 10.1590/ S0100-67622007000600006.

SILVA, M.R. et al. Efeito do manejo hídrico e da aplicação de potássio nas características morfofisiológicas de mudas de Eucalyptus grandis W. (Hill ex. Maiden). Irriga, v.9, p.31-40, 2004. Disponível em: <http://200.145.140.50/ojs1/include/ getdoc.php?id=367\&article=132...pdf $>$. Acesso em: 13 jan. 2011.

VALLADARES, F.; NIINEMETS, Ü. Shade tolerance, a key plant feature of complex nature and consequences. Annual Review of Ecology, Evolution and Systematics, v.39, p.237257, 2008. Disponível em: <http://arjournals.annualreviews.org/ eprint/EWa Tv4 c TbuA 7 F VKS W BuP/fu11/10.1146/ annurev.ecolsys.39.110707.173506>. Acesso em: 22 abr. 2011. doi: 10.1146/annurev.ecolsys.39.110707.173506. 